\title{
Octahedral chalcogenide rhenium cluster complexes with imidazole
}

\author{
Dmitry I. Konovalov, ${ }^{1,2}$ Anton A. Ivanov, ${ }^{1}$ Yuri A. Vorotnikov, ${ }^{1}$ \\ Anton I. Smolentsev, ${ }^{1}$ Ilia V. Eltsov, ${ }^{2}$ Olga A. Efremova, ${ }^{3}$ Noboru Kitamura, ${ }^{4}$ \\ Yuri V. Mironov, ${ }^{1,2}$ Michael A. Shestopalov ${ }^{1,2^{*}}$ \\ ${ }^{1}$ Nikolaev Institute of Inorganic Chemistry SB RAS, 3 Acad. Lavrentiev Ave., 630090 Novosibirsk, \\ Russian Federation, shtopy@niic.nsc.ru \\ ${ }^{2}$ Novosibirsk State University, 2 Pirogova Str., 630090 Novosibirsk, Russian Federation \\ ${ }^{3}$ School of Mathematics and Physical Sciences, University of Hull, Cottingham Road, HU6 7RX, Hull, UK \\ ${ }^{4}$ Department of Chemistry, Faculty of Science, Hokkaido University, 060-0810 Sapporo, Japan
}

\begin{abstract}
Reactions of $\left[\left\{\operatorname{Re}_{6} \mathrm{Q}_{8}\right\} \mathrm{Br}_{6}\right]^{4-/ 3-}(\mathrm{Q}=\mathrm{S}, \mathrm{Se})$ with molten imidazole lead to the formation of two new neutral cluster complexes $\left[\left\{\operatorname{Re}_{6} \mathrm{Q}_{8}\right\}(\mathrm{imzH})_{4}(\mathrm{imz})_{2}\right](\mathrm{imzH}=$ imidazole). The interaction of $\left[\left\{\mathrm{Re}_{6} \mathrm{Q}_{8}\right\}(\mathrm{imzH})_{4}(\mathrm{imz})_{2}\right]$ with hydrohalic acids resulted in cationic complexes $\left[\left\{\mathrm{Re}_{6} \mathrm{Q}_{8}\right\}(\mathrm{imzH})_{6}\right] \mathrm{X}_{2}(\mathrm{X}=\mathrm{Cl}, \mathrm{Br})$. All compounds were characterised by $\mathrm{X}$-ray single-crystal and powder diffraction analyses, elemental analysis, energy dispersive X-ray and IR spectroscopies. The luminescence of the neutral compounds $\left[\left\{\mathrm{Re}_{6} \mathrm{Q}_{8}\right\}(\mathrm{imzH})_{4}(\mathrm{imz})_{2}\right]$ was also studied.
\end{abstract}

Key words: Rhenium cluster; Imidazole; Crystal structure; Luminescence;

\section{Introduction}

Octahedral rhenium cluster complexes of the general formula $\left[\left\{\operatorname{Re}_{6} \mathrm{Q}_{8}\right\} \mathrm{L}_{6}\right]^{\mathrm{n}}$ (where $\mathrm{Q}$ is $\mathrm{S}$ or $\mathrm{Se}$, and $\mathrm{L}$ are either inorganic or organic terminal ligands) and related cluster-based materials have attracted significant attention of researchers due to the unique combination of properties that they possess. This includes phosphorescence in the red/near-infrared region upon UV/blue light excitation [1-6], electroluminescence [7], their ability to generate singlet oxygen [8-10] and high $\mathrm{X}$-ray attenuation efficacy [11-12]. This set of properties opens an avenue to applications such as materials for light emitted diodes [7], photoactive liquid crystals [13-14], optical bioimaging [910, 15-16], photodynamic therapy[10], imaging agents for X-ray computed tomography [11-12] and others [17-23].

Notably, by replacing the terminal ligands L, one can both fine-tune the photophysical properties of the octahedral rhenium clusters and target them to a specific application. For example, to target biomedical applications, it is possible to synthesise compounds with ligands bearing functional groups such as $-\mathrm{NH}_{2},-\mathrm{COOH},-\mathrm{CONH}_{2}$ [24-28] i.e. groups open for further modification or cleaving to biological molecules. Alternatively, furnishing the clusters with polymerisable ligands gives an opportunity to use the octahedral rhenium clusters as the active components of processable luminescent polymers [7, 29-30]. Synthesis of the metal clusters with simple heterocyclic ligands [9, 31-34] are also of interest, as such compounds that can lead to additional properties, which include supramolecular, porous crystalline structures [35-37] or versatile redox properties [27]. Moreover, the study of octahedral complexes with simple heterocycles that are related to biological molecules such as nucleotides and amino-acids may uncover the potential of these compound as, for example, anticancer agents [38].

(C2019, Elsevier. This manuscript version is made available under the CC-BY-NC-ND 4.0 license http://creativecommons.org/licenses/by-nc-nd/4.0/ 
In this work we report the synthesis, structures and luminescent properties of new neutral octahedral rhenium cluster complexes that have imidazole ligands, which is an important biological building block (e.g. the amino acid, histidine, and the related hormone, histamine, which both contain imidazole rings). Specifically, here we demonstrate the neutral cluster compounds $\left[\left\{\operatorname{Re}_{6} \mathrm{Q}_{8}\right\}(\mathrm{imzH})_{4}(\mathrm{imz})_{2}\right]$, in which cluster cores $\left\{\operatorname{Re}_{6} \mathrm{Q}_{8}\right\}^{2+}(\mathrm{Q}=\mathrm{S}(\mathbf{1})$ or Se $(\mathbf{2}))$ are coordinated by four imidazole (imzH) and two imidazolide (imz) ligands. Both compounds were obtained in just one stage by heating $\mathrm{Cs}_{4}\left[\left\{\mathrm{Re}_{6} \mathrm{~S}_{8}\right\} \mathrm{Br}_{6}\right] \cdot 2 \mathrm{H}_{2} \mathrm{O}$ or $\mathrm{Cs}_{3}\left[\left\{\mathrm{Re}_{6} \mathrm{Se}_{8}\right\} \mathrm{Br}_{6}\right] \cdot 2 \mathrm{H}_{2} \mathrm{O}$, respectively, in molten imidazole. It should be noted that the compounds' two imidozolide ligands retained significant basic properties, which allowed us to also obtain cationic cluster compounds $\left[\left\{\operatorname{Re}_{6} \mathrm{Q}_{8}\right\}(\mathrm{imzH})_{6}\right] \mathrm{X}_{2}(\mathrm{X}=\mathrm{Cl}, \mathrm{Br})$ by the reaction of $\left[\left\{\mathrm{Re}_{6} \mathrm{Q}_{8}\right\}(\mathrm{imzH})_{4}(\mathrm{imz})_{2}\right]$ with hydrohalic acids.

\section{Experimental}

\subsection{Materials and methods}

All reagents and solvents were commercially available and they were used without additional purification. The caesium salts $\mathrm{Cs}_{n}\left[\left\{\operatorname{Re}_{6} \mathrm{Q}_{8}\right\} \mathrm{Br}_{6}\right] \cdot 2 \mathrm{H}_{2} \mathrm{O}(\mathrm{Q}=\mathrm{S}$ and $\mathrm{n}=4$ or $\mathrm{Q}=\mathrm{Se}$ and $\mathrm{n}=3)$ were obtained according to the literature procedure [39-40].

Elemental analyses were performed on a EuroVector EA3000 Elemental Analyzer. Infrared spectra were recorded as KBr pellets with a Bruker Vertex 80 spectrometer from 400 to $4000 \mathrm{~cm}^{-1}$. Energy-dispersive X-ray spectroscopy (EDS) was performed on a Hitachi TM3000 TableTop SEM with a Bruker QUANTAX 70 EDS equipment with results reported as the ratio of the heavy elements: $\mathrm{Re}, \mathrm{S} / \mathrm{Se}$, and $\mathrm{X}$; the relative error of the method was about $5 \%$. The thermal properties were studied on a Thermo Microbalance TG 209 F1 Iris (NETZSCH) from 25 to $850{ }^{\circ} \mathrm{C}$ with a rate of $10^{\circ} \mathrm{min}^{-1}$ in He flow $\left(30 \mathrm{~mL} \mathrm{~min}^{-1}\right)$. X-ray powder diffraction (XRPD) data were collected on a Shimadzu XRD 7000S using $\mathrm{CuK}_{\alpha}$ radiation $(\lambda=1.5406 \AA)$ and a graphite monochromator.

\subsection{Synthesis of compounds}

\section{General Proce dure for Syntheses of Compounds.}

Synthesis of $\left[\left\{\mathrm{Re}_{6} \mathrm{~S}_{8}\right\}(\mathrm{imz} H)_{4}(\mathrm{imz})_{2}\right]$ (1): $\mathrm{Cs}_{4}\left[\left\{\mathrm{Re}_{6} \mathrm{~S}_{8}\right\} \mathrm{Br}_{6}\right] \cdot 2 \mathrm{H}_{2} \mathrm{O}(200 \mathrm{mg}, 0.0826 \mathrm{mmol})$ and imidazole (200 mg, $2.938 \mathrm{mmol}$ ) were heated in a sealed glass tube at $180{ }^{\circ} \mathrm{C}$ for 2 days. The reaction product was washed with water and dried in air. The amorphous product was dissolved in $10 \mathrm{~mL}$ water-ethanol solution $(\mathrm{v} / \mathrm{v}=1: 1)$ containing $\sim 30 \mathrm{mg}$ of $\mathrm{KOH}$ and precipitated by the addition of water, washed with water and dried on air. Yield: $118 \mathrm{mg}(80 \%)$. For $\mathrm{C}_{18} \mathrm{H}_{22} \mathrm{~N}_{12} \mathrm{Re}_{6} \mathrm{~S}_{8}$ (1) calculated: C, 12.1; H, 1.2; N, 9.4; S, 14.3; found: C, 12.1; H, 1.3; N, 9.2; S, 14.1. EDS: Re : S $: \mathrm{Br}=6: 7.8: 0$.

Synthesis of $\left[\left\{\mathrm{Re}_{6} \mathrm{Se}_{8}\right\}(\mathrm{imzH})_{4}(\mathrm{imz})_{2}\right]$ (2): The compound was obtained similarly to $\mathbf{1}$ by the reaction of $\mathrm{Cs}_{3}\left[\left\{\mathrm{Re}_{6} \mathrm{Se}_{8}\right\} \mathrm{Br}_{6}\right] \cdot 2 \mathrm{H}_{2} \mathrm{O}(200 \mathrm{mg}, 0.0751 \mathrm{mmol})$ with imidazole $(200 \mathrm{mg}, 2.938 \mathrm{mmol})$ Yield: $138 \mathrm{mg}$ (85\%). For $\mathrm{C}_{18} \mathrm{H}_{22} \mathrm{~N}_{12} \mathrm{Re}_{6} \mathrm{Se}_{8}$ (2) calculated: C, 10.0; H, 1.0; N, 7.8; found: C, 10.0; H, 1.2; N, 7.8. EDS: Re: $\mathrm{Se}: \mathrm{Br}=6: 7.9: 0$.

Protonation of cluster complexes [\{ $\left.\left.\mathrm{Re}_{6} \mathrm{~S}_{8}\right\}(\mathrm{imz} H)_{6}\right] \mathrm{X}_{2} \cdot 4 \mathrm{DMSO} \quad(\mathbf{1} \cdot 2 \mathrm{HX} \cdot 4 \mathrm{DMSO})$ and [\{ $\left.\left.\operatorname{Re}_{6} \mathrm{Se}_{8}\right\}(\mathrm{imzH})_{6}\right] \mathrm{X}_{2} \cdot 4 \mathrm{DMSO}(2 \cdot 2 \mathrm{HX} \cdot 4 \mathrm{DMSO}):\left[\left\{\mathrm{Re}_{6} \mathrm{Q}_{8}\right\}(\mathrm{imzH})_{4}(\mathrm{imz})_{2}\right](50 \mathrm{mg})$ was dissolved (C2019, Elsevier. This manuscript version is made available under the CC-BY-NC-ND 4.0 license http://creativecommons.org/licenses/by-nc-nd/4.0/ 
in DMSO $(2 \mathrm{ml})$, where a few drops of $\mathrm{HX}_{\text {conc. }}(\mathrm{X}=\mathrm{Cl}, \mathrm{Br})$ were added. The resultant cluster complexes $\quad\left[\left\{\mathrm{Re}_{6} \mathrm{Q}_{8}\right\}(\mathrm{imzH})_{6}\right] \mathrm{X}_{2} \cdot 4 \mathrm{DMSO} \quad(\mathbf{1} \cdot 2 \mathrm{HCl} \cdot 4 \mathrm{DMSO}$ and $\mathbf{1} \cdot 2 \mathrm{HBr} \cdot 4 \mathrm{DMSO}$, $2 \cdot 2 \mathrm{HCl} \cdot 4 \mathrm{DMSO}$ and $2 \cdot 2 \mathrm{HBr} \cdot 4 \mathrm{DMSO}$ ) were precipitated by the addition of $50 \mathrm{ml}$ of ethyl acetate. The product was quantitatively isolated by centrifuging, washed with ethyl acetate and dried in air. Yields: $\sim 100 \%$. For $\mathrm{C}_{26} \mathrm{H}_{48} \mathrm{Cl}_{2} \mathrm{~N}_{12} \mathrm{O}_{4} \mathrm{Re}_{6} \mathrm{~S}_{12}(\mathbf{1} \cdot 2 \mathrm{HCl} \cdot 4 \mathrm{DMSO})$ calculated: C, 14.4; H, 2.2; N, 7.8; S, 17.8; found: C, 14.3; H, 2.3; N, 7.8; S, 17.7. For $\mathrm{C}_{26} \mathrm{H}_{48} \mathrm{Br}_{2} \mathrm{~N}_{12} \mathrm{O}_{4} \mathrm{Re}_{6} \mathrm{~S}_{12}(1 \cdot 2 \mathrm{HBr} \cdot 4 \mathrm{DMSO})$ calculated: C, 13.8; H, 2.1; N, 7.4; S, 17.0; found: C, 14.0; H, 1.9; N, 7.5; S, 16.9. EDS: Re : S : $\mathrm{X}$ ratio is $6: 12.1: 1.9$ for $1 \cdot 2 \mathrm{HCl} \cdot 4 \mathrm{DMSO}$ and $6: 11.8: 1.9$ for $1 \cdot 2 \mathrm{HBr} \cdot 4 \mathrm{DMSO}$. For $\mathrm{C}_{26} \mathrm{H}_{48} \mathrm{Cl}_{2} \mathrm{~N}_{12} \mathrm{O}_{4} \mathrm{Re}_{6} \mathrm{~S}_{4} \mathrm{Se}_{8}(2 \cdot 2 \mathrm{HCl} \cdot 4 \mathrm{DMSO})$ calculated: C, 12.2; H, 1.9; N, 6.6; S, 5.0; found: C, 12.3; H, 2.1; N, 6.8; S, 4.7. For $\mathrm{C}_{26} \mathrm{H}_{48} \mathrm{Br}_{2} \mathrm{~N}_{12} \mathrm{O}_{4} \mathrm{Re}_{6} \mathrm{~S}_{4} \mathrm{Se}_{8}$ (2.2HBr.4DMSO) calculated: C, 11.9; $\mathrm{H}, 1.8 ; \mathrm{N}, 6.4 ; \mathrm{S}, 4.9$; found: $\mathrm{C}, 12.0 ; \mathrm{H}, 1.8 ; \mathrm{N}, 6.5 ; \mathrm{S}, 4.9$. EDS: Re : Se : X ratio is $6: 7.9: 2$ for $2 \cdot 2 \mathrm{HCl} \cdot 4 \mathrm{DMSO}$ and $6: 8.1: 1.9$ for $2 \cdot 2 \mathrm{HBr} \cdot 4 \mathrm{DMSO}$.

\section{X-ray crystallography}

Single-crystal X-ray diffraction data for 1, 1·2DMSO, 2·2HCl-4DMSO and 2·2HBr-4DMSO were collected using graphite monochromatised Mo $\mathrm{K}_{\alpha}$-radiation $(\lambda=0.71073 \AA)$ at $150(2) \mathrm{K}$ on a Bruker-Nonius X8 APEX diffractometer equipped with a 4 K CCD area detector. The $\varphi$-scan technique was employed to measure intensities. Absorption corrections were made empirically using the SADABS program [41]. The structures were solved by the direct method and further refined by the full-matrix least-squares method using the SHELXTL program package [41]. All non-hydrogen atoms were refined anisotropically. Table 1 summarises crystallographic data, while CCDC 1890750-1890753 contain the supplementary crystallographic data for this paper. These data can be obtained free of charge from the Cambridge Crystallographic Data Centre via www.ccdc.cam.ac.uk/data_request/cif.

\section{3. $\quad$ Luminescence measurements}

For the emission measurements, the powdered samples were placed between two non-fluorescent glass plates. The absorbance of the cluster solutions was set at $<0.1$ at $355 \mathrm{~nm}$. The solutions were poured into a quartz cuvette and deaerated by purging with an Ar-gas stream for $30 \mathrm{~min}$, and then the cuvettes were sealed. Measurements were carried out at $298 \mathrm{~K}$. The samples were excited by laser pulses with a wavelength of 355-nm (6 ns duration, LOTIS TII, LS-2137/3). Corrected emission spectra were recorded on a red-light-sensitive multichannel photodetector (Hamamatsu Photonics, PMA-12). For the emission decay measurements, the emission was analysed by a streakscope system (Hamamatsu Photonics, C4334 and C5094). To calculate the lifetime parameters the luminescence intensity decays were fitted by using the u8167-01 software supplied with the streakscope system by Hamamatsu Company. Emission quantum yields were determined at the excitation wavelength of $400 \mathrm{~nm}$ by an Absolute Photo-Luminescence Quantum Yield Measurement System (Hamamatsu Photonics, C9920-03), which comprised an excitation Xenon light source, an integrating sphere, and a red-sensitive multichannel photodetector (Hamamatsu Photonics, PMA-12). The luminescence spectra were smoothed by the Savitzky-Golay filter to increase the signal-to-noise ratio [42].

\section{Results and discussion}

(C2019, Elsevier. This manuscript version is made available under the CC-BY-NC-ND 4.0 license http://creativecommons.org/licenses/by-nc-nd/4.0/ 


\section{1. $\quad$ Synthesis and general characterization of cluster complexes with imidazole}

The reactions of octahedral halide clusters in molten organic pro-ligands, where they serve as both a reactant and a reaction medium, have proven themselves as a simple way to obtain new octahedral cluster complexes with organic ligands. [25, 31-32, 40, 43-44] Furthermore, it was noted earlier that the ability of the organic pro-ligands to self-ionise (i.e. whether they have protic or aprotic properties) predetermines the charge and the number of apical ligands in the final product [40]. Namely, the driving force in the reactions of the clusters with aprotic pro-ligands is the formation of the neutral complex, which are more stable in the non-ionic melt. In this case, only four halide ligands are substituted to give the total neutral charge. On the other hand, the reactions with protic pro-ligands lead to the formation of hexa-substituted complexes, such as these few examples reported earlier: $\left[\left\{\mathrm{Re}_{6} \mathrm{Q}_{8}\right\}\left(\mathrm{PPh}_{2} \mathrm{CH}_{2} \mathrm{CH}_{2} \mathrm{COOH}\right)_{6}\right] \mathrm{Br}_{2} \cdot \mathrm{H}_{2} \mathrm{O}[28]$ and $\left[\left\{\mathrm{Re}_{6} \mathrm{Q}_{8}\right\}(3,5-\right.$ $\left.\left.\mathrm{Me}_{2} \mathrm{pzH}\right)_{6}\right] \mathrm{Br}_{2} \cdot 2\left(3,5-\mathrm{Me}_{2} \mathrm{pzH}\right)$ [31] (Q = S and Se, 3,5-Me $\mathrm{M}_{2} \mathrm{pH}=3$,5-dimethylpyrazole). The formation of hexa-substituted complexes is believed to be due to the ability of protic molecules to stabilise charged species in melt via self-ionisation. The reactions with such pro-ligands are thus driven only by the chemical potential of the pro-ligand, which is significant when pro-ligand is used as a reaction solvent.

In accordance with this hypothesis, the reactions of caesium salts of octahedral chalcohalide rhenium cluster complexes $\mathrm{Cs}_{n}\left[\left\{\operatorname{Re}_{6} \mathrm{Q}_{8}\right\} \mathrm{Br}_{6}\right] \cdot 2 \mathrm{H}_{2} \mathrm{O}(\mathrm{Q}=\mathrm{S}, \mathrm{n}=4$ or $\mathrm{Q}=\mathrm{Se}, \mathrm{n}=3)$ in molten imidazole (which is a protic pro-ligand) also produced hexa-substituted compounds (Scheme 1, Reaction $(i)$ ). Indeed, according to EDX, the amorphous reaction products obtained by washing the reaction mixture with water contained only around $0.5 \mathrm{Br}$ per cluster unit and no caesium. The dissolution of these products in a water-ethanol mixture containing $\mathrm{KOH}$ and their precipitation by the addition of more water yielded neutral compounds $\left[\left\{\operatorname{Re}_{6} \mathrm{Q}_{8}\right\}(\mathrm{imzH})_{4}(\mathrm{imz})_{2}\right]$, where $\mathrm{Q}=\mathrm{S}$ (1) or Se (2), Reaction (ii). EDX revealed no traces of Br, while elemental analyses were in good agreement with the suggested formula. Powder XRD of 1 and $\mathbf{2}$ (Fig. S1) revealed that they both contain single crystalline phases, since the reflections coincide with those generated from crystal structure of 1 as discussed below. FTIR (400-4000 $\mathrm{cm}^{-1}$ ) of both precipitates had all of the peaks that were expected for imidazole, while that of 1 also showed the band at $413 \mathrm{~cm}^{-1}$ assigned to Re$\left(\mu_{3}-\mathrm{S}\right)$ vibration (Fig. S2). We thus believe that in the reaction with molten imidazole both neutral $\left[\left\{\operatorname{Re}_{6} \mathrm{Q}_{8}\right\}(\mathrm{imzH})_{4}(\mathrm{imz})_{2}\right]$ and admixture of cationic $\left[\left\{\mathrm{Re}_{6} \mathrm{Q}_{8}\right\}(\mathrm{imzH})_{6}\right] \mathrm{Br}_{2}$ were formed with the latter chemical form being eliminated in the consequent dissolution with $\mathrm{KOH}$.

It was also possible to obtain pure protonated form of the compounds, $\left[\left\{\operatorname{Re}_{6} \mathrm{Q}_{8}\right\}(\mathrm{imzH})_{6}\right]^{2+}$, by the reactions of $\mathbf{1}$ and $\mathbf{2}$ with hydrohalic acids in DMSO, Reaction (iii). Indeed, we noticed that the solubility of compounds is significantly better in acidified DMSO than in pure DMSO. During the reactions, deprotonated ligands were protonated to give cluster di-cations. Such protonated forms of the clusters can be also obtained by the dissolution of the products of Reaction ( $i$ ) with HX in DMSO, Reaction (iv), while the cationic clusters can be converted into the neutral ones using the same method as in Reaction (ii), i.e. by the treatment of the cationic cluster complexes with waterethanol solution of $\mathrm{KOH}$, Reaction (v). Protonation/deprotonation of the rhenium clusters with imidazole are therefore reversible processes. Unfortunately, we were not able to obtain the crystal structure of compound containing $\left[\left\{\mathrm{Re}_{6} \mathrm{~S}_{8}\right\}(\mathrm{imzH})_{6}\right]^{2+}$ salts, while $\left[\left\{\mathrm{Re}_{6} \mathrm{Se}_{8}\right\}(\mathrm{imzH})_{6}\right]^{2+}$ were 
successfully crystallised with chloride and bromide counter-ions and characterised by single crystal analysis as $\mathbf{2} \cdot 2 \mathrm{HX} \cdot 4 \mathrm{DMSO}$, where $\mathrm{X}=\mathrm{Cl}$ or Br. Nevertheless, powder XRD patterns of 1.2HX-4DMSO and $2 \cdot 2 \mathrm{HX} \cdot 4 \mathrm{DMSO}$ were in good agreement with the theoretical diffractograms calculated from structural data of 2·2HX·4DMSO (Fig. S3).

Thermogravimetric analysis (TGA) confirmed that $\mathbf{1}$ and $\mathbf{2}$ are thermodynamically preferable products of the reaction in molten imidazole as they are stable all the way up to above $200^{\circ} \mathrm{C}$ (Fig. S4). In the temperature range $200-800^{\circ} \mathrm{C}$ both cluster complexes undergo two step decomposition, with the first step starting from just above $200{ }^{\circ} \mathrm{C}$ and the second step from above $550^{\circ} \mathrm{C}$. In contrast, TGA of solvates, $1 \cdot 2 \mathrm{HBr} \cdot 4 \mathrm{DMSO}$ and $2 \cdot 2 \mathrm{HBr} \cdot 4 \mathrm{DMSO}$, revealed that both start decomposing at $100{ }^{\circ} \mathrm{C}$, likely with the removal of two $\mathrm{HBr}$ molecules (first step in the TGA curve on Fig. S5), followed by removal of DMSO molecules and decomposition of the cluster complexes.

\section{2. $\quad$ Crystal structure of compounds with imidazole ligands}

Single crystals of $\mathbf{1}$ for X-ray structural analyses were obtained by two different techniques: 1) by slow evaporation of water-ethanol solution $(\mathrm{v} / \mathrm{v}=1: 1)$ containing a small amount of $\mathrm{KOH}$ to give crystals of $\mathbf{1}$ and 2) by diffusion of ethyl acetate into solution of $\mathbf{1}$ in DMSO to give crystals of solvate 1.2DMSO. Single crystals of the protonated form of $\mathbf{2}$, were obtained as solvates $2 \cdot 2 \mathrm{HCl} \cdot 4 \mathrm{DMSO}$ and $2 \cdot 2 \mathrm{HBr} \cdot 4 \mathrm{DMSO}$ by the diffusion of ethyl acetate into the solution of $\mathbf{2}$, containing hydrohalic acid in DMSO.

According to single crystal analyses the molecular structures of all cluster compounds in all crystalline phases are in accordance with the suggested formula. Specifically, they contain octahedral cluster cores $\left\{\operatorname{Re}_{6} \mathrm{Q}_{8}\right\}^{2+}(\mathrm{Q}=\mathrm{S}$ or $\mathrm{Se})$, similar to starting octahedral clusters and other related compounds. Each cluster core represents a $\operatorname{Re}_{6}$ octahedron with all faces capped by $\mu_{3}-\mathrm{Q}$ atoms. Each of the rhenium atom in the clusters are also coordinated by imidazole or imidazolium ligands via nitrogen atoms (Fig. 1). Re-Re, Re-Q and Re-N bond lengths in the crystalline compounds are presented in Table $\mathrm{S} 1$ and are in a good agreement with the literature data for hexanuclear rhenium cluster complexes with $\mathrm{N}$-donor heterocycles [5, 9, 25, 31-32, 45]. Overall, in the crystal structures the idealised $O_{h}$ point symmetry of the clusters are reduced down to $C i$ in $\mathbf{1}$ and $2 \cdot 2 \mathrm{HCl} \cdot 4 \mathrm{DMSO}$ or $C_{2 v}$ in 1.2DMSO with all atoms in the cluster complexes being in the general crystallographic positions.

Despite being quite different from the crystallographic point of view, i.e. crystallising in different crystal systems: triclinic and monoclinic, respectively, compounds $\mathbf{1}$ and 1·2DMSO-are relatively similar not only from molecular point of view but also from supramolecular bonding topology. To satisfy the neutral cluster complex stoichiometry, cluster cores in $\mathbf{1}$ and 1.2DMSO were coordinated by two imidazolium and four imidazole ligands. In both of the structures, four of the planar organic ligands represent a mixture of two ImzH and two Imz ligands. In 1, this disorder is achieved by two crystallographically independent hydrogen atoms being equally distributed over four positions associated with non-coordinating nitrogen atoms, while in case of 1.2DMSO there is one crystallographically independent hydrogen atom that is distributed over two positions. These disordered hydrogen atoms are involved in strong $\mathrm{N}-\mathrm{H} \cdots \mathrm{N}$ hydrogen bond interactions between 
adjacent complexes. These hydrogen bond interactions are demonstrated by the relatively short N... N distances: 2.729 and $2.984 \AA$ in compound 1 (Fig. 2B and 2C) and $2.665 \AA$ and $2.706 \AA$ in compound 1-2DMSO (Fig. 3A). Such disorder can be thus described as hydrogen atoms being shared between two planar imidazolium ions of neighbouring clusters, which give rise to extended 2D layered grids with metal clusters located in the nodes of the grids (Fig. 2A and S6).

The packing of the $2 \mathrm{D}$ grids is, however, different. In compound $\mathbf{1}$, the hydrogen bonded layers are stacked and further crosslinked by $\pi-\pi$ stacking interactions (3.470, 3.647 and $4.239 \AA$ A between the ring centres) (Fig. S7) that form a strongly packed structure. Unlike compound 1, the independent part in 1.2DMSO also contains one solvate molecule of DMSO, which is disordered over two crystallographic positions, with calculated occupancies of 0.6 and 0.4 , respectively. These solvated DMSO molecules distort $\pi-\pi$ stacking of the $2 \mathrm{D}$ grids. Instead, $\mathrm{N}-\mathrm{H} \cdots \mathrm{O}$ hydrogen bonds are formed between imidazole ligands in axial positions and DMSO molecules with distances of 2.699 and $2.769 \AA$ (Fig. 3B).

Both cluster compounds $2 \cdot 2 \mathrm{HX} \cdot 4 \mathrm{DMSO}(\mathrm{X}=\mathrm{Cl}, \mathrm{Br})$ are isostructural and contain half of the centre-symmetrical cluster cation $\left[\left\{\mathrm{Re}_{6} \mathrm{Se}_{8}\right\}(\mathrm{imzH})_{6}\right]^{2+}$, a halide anion $\left(\mathrm{Cl}^{-} \mathrm{or} \mathrm{Br}^{-}\right)$and two solvate molecules of DMSO in the independent part. Since all nitrogen atoms of the ligands were protonated, the clusters were not hydrogen-bonded to each other. Instead, protons associated with the non-coordinating nitrogen atoms of imidazole ligands are involved in the developed network of hydrogen bonding that includes both $\mathrm{O}$ atoms of DMSO molecules and halide ions (Fig. 4). The

$\mathrm{N}-\mathrm{H} \cdots \mathrm{X}$ hydrogen bonds are characterised by N$\cdots \mathrm{X}$ distances in the range of 3.143-3.163 $\AA$ for $\mathrm{X}=\mathrm{Cl}$ and 3.310-3.276 $\AA$ for $\mathrm{X}=\mathrm{Br}$. The $\mathrm{N}-\mathrm{H} \cdots \mathrm{O}$ bonds are $\mathrm{O}$ distances of $2.674 \AA$ for 2.2HCl-4DMSO and $2.747 \AA$ for $2 \cdot 2 \mathrm{HBr} \cdot 4 \mathrm{DMSO}$.

\subsection{Photophysical properties}

Similar to other octahedral rhenium clusters with $\left\{\operatorname{Re}_{6} Q_{8}\right\}^{2+}$ both compounds $\mathbf{1}$ and $\mathbf{2}$ are luminescent with broad emission spectra spreading from 550 to more than $950 \mathrm{~nm}$ in the solid state and in DMSO solution (Fig. 5). Table 2 summarises photophysical characteristics, i.e. emission maximum wavelengths $\left(\lambda_{\mathrm{em}}\right)$, emission lifetimes $\left(\tau_{\mathrm{em}}\right)$ and quantum yields $\left(\Phi_{\mathrm{em}}\right)$ of $\mathbf{1}$ and 2 in both the solid state and DMSO solutions. One can note from the data that the emission profile of cluster complex $\mathbf{2}$ is slightly blue-shifted and somewhat narrower in comparison with that of $\mathbf{1}$. Such differences between the sulphide and selenide rhenium clusters are quite typical and demonstrate the decrease of the energy gap between the emissive triplet state and the excited singlet state for metal clusters with the heavier chalcogen in the core [1, 3-5, 46]. Triple exponential decay fitting of the luminescence lifetimes of the powdered samples (Fig. S8) is also common for luminescent octahedral clusters in the solid state and it is usually explained by efficient excitation migration in the crystal and subsequent energy trapping and emission in the crystal defects [46]. Finally, a significant increase of both $\tau_{\mathrm{em}}$ and $\Phi_{\mathrm{em}}$ values were observed for both compounds after degasification by purging with argon, which indicates the typical property of most of the known photoluminescent octahedral cluster complexes, i.e. quenching by molecular oxygen [8-9].

\section{Conclusions}

(C2019, Elsevier. This manuscript version is made available under the CC-BY-NC-ND 4.0 license http://creativecommons.org/licenses/by-nc-nd/4.0/ 
Four new rhenium cluster complexes with imidazole ligands were synthesised by a very simple technique that uses a molten $n$-donor organic pro-ligand as both reactant and reaction medium for octahedral rhenium chalcobromide clusters. The compositions of the products, $\left[\left\{\operatorname{Re}_{6} \mathrm{Q}_{8}\right\}(\mathrm{imzH})_{4}(\mathrm{imz})_{2}\right](\mathrm{Q}=\mathrm{S}, \mathrm{Se})$, are in the agreement with the earlier suggestion: reactions of octahedral rhenium clusters in molten protic ligands are likely to result in hexa-substituted cluster complexes. Notably, in the solid-state neutral metal clusters are bonded with each other via hydrogen bonds formed between imidazole and imidazolide ligands producing supramolecular 2D grid structures. The grids are further bonded via $\pi-\pi$ stackings of imidazole rings of parallel grids. Solvation of $\left[\left\{\operatorname{Re}_{6} \mathrm{Q}_{8}\right\}(\mathrm{imzH})_{4}(\mathrm{imz})_{2}\right]$ with DMSO affects the packing of the grids by intercalating between the grids and preventing the formation of $\pi$ - $\pi$ stackings. The fully protonated cationic species were also produced and isolated in pure crystalline form for the selenide cluster in the form of $\left[\left\{\mathrm{Re}_{6} \mathrm{Se}_{8}\right\}(\mathrm{imzH})_{6}\right] \mathrm{X}_{2}(\mathrm{X}=\mathrm{Cl}, \mathrm{Br})$ by the addition of $\mathrm{HX}$ acid to the DMSO solution of neutral compound. The study of luminescent properties revealed a characteristic blue-shift of emission maximum of selenium compound in comparison with that of sulphur one with absolute quantum yields of 0.11 for $\left[\left\{\operatorname{Re}_{6} \mathrm{~S}_{8}\right\}(\mathrm{imzH})_{4}(\mathrm{imz})_{2}\right]$ and 0.06 for $\left[\left\{\mathrm{Re}_{6} \mathrm{Se}_{8}\right\}(\mathrm{imzH})_{4}(\mathrm{imz})_{2}\right]$ in solid state and 0.12 and 0.14 in deaerated DMSO solutions, respectively.

\section{Acknowledgments}

This research was supported by the Russian Foundation for Basic Research (Grant No. 18-3300025).

\section{References}

1. N. Kitamura, Y. Ueda, S. Ishizaka, K. Yamada, M. Aniya, Y. Sasaki, Inorg. Chem. 44 (2005) 6308-6313.

2. L.F. Szczepura, D.L. Cedeño, D.B. Johnson, R. McDonald, S.A. Knott, K.M. Jeans, J.L. Durham, Inorg. Chem. 49 (2010) 11386-11394.

3. T. Yoshimura, S. Ishizaka, Y. Sasaki, H.-B. Kim, N. Kitamura, N.G. Naumov, M.N. Sokolov, V.E. Federov, Chem. Lett. 28 (1999) 1121-1122.

4. T. Yoshimura, A. Matsuda, Y. Ito, S. Ishizaka, S. Shinoda, H. Tsukube, N. Kitamura, A. Shinohara, Inorg. Chem. 49 (2010) 3473-3481.

5. T. Yoshimura, C. Suo, K. Tsuge, S. Ishizaka, K. Nozaki, Y. Sasaki, N. Kitamura, A. Shinohara, Inorg. Chem. 49 (2010) 531-540.

6. A.A. Ivanov, C. Falaise, P.A. Abramov, M.A. Shestopalov, K. Kirakci, K. Lang, M.A. Moussawi, M.N. Sokolov, N.G. Naumov, S. Floquet, D. Landy, M. Haouas, K.A. Brylev, Y.V. Mironov, Y. Molard, S. Cordier, E. Cadot, Chem. Eur. J. 24 (2018) 13467-13478.

7. O.A. Efremova, K.A. Brylev, O. Kozlova, M.S. White, M.A. Shestopalov, N. Kitamura, Y.V. Mironov, S. Bauer, A.J. Sutherland, J. Mater. Chem. C 2 (2014) 8630-8638

8. L. Gao, M.A. Peay, T.G. Gray, Chem. Mater. 22 (2010) 6240-6245.

9. M.A. Shestopalov, K.E. Zubareva, O.P. Khripko, Y.I. Khripko, A.O. Solovieva, N.V. Kuratieva, Y.V. Mironov, N. Kitamura, V.E. Fedorov, K.A. Brylev, Inorg. Chem. 53 (2014) 90069013.

10. A.O. Solovieva, K. Kirakci, A.A. Ivanov, P. Kubát, T.N. Pozmogova, S.M. Miroshnichenko, E.V. Vorontsova, A.V. Chechushkov, K.E. Trifonova, M.S. Fufaeva, E.I. Kretov, Y.V. Mironov, A.F. Poveshchenko, K. Lang, M.A. Shestopalov, Inorg. Chem. 56 (2017) 13491-13499.

(C2019, Elsevier. This manuscript version is made available under the CC-BY-NC-ND 4.0 license http://creativecommons.org/licenses/by-nc-nd/4.0/ 
11. A.A. Krasilnikova, M.A. Shestopalov, K.A. Brylev, I.A. Kirilova, O.P. Khripko, K.E. Zubareva, Y.I. Khripko, V.T. Podorognaya, L.V. Shestopalova, V.E. Fedorov, Y.V. Mironov, J. Inorg. Biochem. 144 (2015) 13-17.

12. A.A. Krasilnikova, A.O. Solovieva, A.A. Ivanov, K.E. Trifonova, T.N. Pozmogova, A.R. Tsygankova, A.I. Smolentsev, E.I. Kretov, D.S. Sergeevichev, M.A. Shestopalov, Y.V. Mironov, A.M. Shestopalov, A.F. Poveshchenko, L.V. Shestopalova, Nanomedicine: NBM 13 (2017) 755763.

13. F. Camerel, F. Kinloch, O. Jeannin, M. Robin, S.K. Nayak, E. Jacques, K.A. Brylev, N.G. Naumov, Y. Molard, Dalton Trans. 47 (2018) 10884-10896.

14. Y. Molard, A. Ledneva, M. Amela-Cortes, V. Cîrcu, N.G. Naumov, C. Mériadec, F. Artzner, S. Cordier, Chem. Mater. 23 (2011) 5122-5130.

15. A.A. Krasilnikova, A.O. Solovieva, A.A. Ivanov, K.A. Brylev, T.N. Pozmogova, M.A. Gulyaeva, O.G. Kurskaya, A.Y. Alekseev, A.M. Shestopalov, L.V. Shestopalova, A.F. Poveshchenko, O.A. Efremova, Y.V. Mironov, M.A. Shestopalov, Toxicol Res. 6 (2017) 554-560. 16. J.G. Elistratova, K.A. Brylev, A.O. Solovieva, T.N. Pozmogova, A.R. Mustafina, L.V. Shestopalova, M.A. Shestopalov, V.V. Syakayev, A.A. Karasik, O.G. Sinyashin, J. Photochem. Photobiol. A 340 (2017) 46-52.

17. A.M. Bruck, J. Yin, X. Tong, E.S. Takeuchi, K.J. Takeuchi, L.F. Szczepura, A.C. Marschilok, Inorg. Chem. 57 (2018) 4812-4815.

18. J. Elistratova, B. Akhmadeev, A. Gubaidullin, M.A. Shestopalov, A. Solovieva, K. Brylev, K. Kholin, I. Nizameev, I. Ismaev, M. Kadirov, A. Mustafina, Mater. Design 146 (2018) 49-56.

19. P. Kumar, N.G. Naumov, R. Boukherroub, S.L. Jain, Appl. Cat. A 499 (2015) 32-38.

20. S. Nagashima, S. Furukawa, S. Kamiguchi, R. Kajio, H. Nagashima, A. Yamaguchi, M. Shirai, H. Kurokawa, T. Chihara, J. Clust. Sci. 25 (2014) 1203-1224.

21. S. Nagashima, H. Nagashima, S. Furukawa, S. Kamiguchi, H. Kurokawa, T. Chihara, Appl. Catal. A 497 (2015) 167-175.

22. E. Rojas-Mancilla, A. Oyarce, V. Verdugo, Z. Zheng, R. Ramírez-Tagle, Int. J. Mol. Sci. 16 (2015) 1728-1735.

23. L.D. Estrada, E. Duran, M. Cisterna, C. Echeverria, Z. Zheng, V. Borgna, N. ArancibiaMiranda, R. Ramírez-Tagle, BioMetals 31 (2018) 517-525.

24. W.C. Corbin, G.S. Nichol, Z. Zheng, J. Clust. Sci. 26 (2015) 279-290.

25. A.A. Ivanov, V.K. Khlestkin, K.A. Brylev, I.V. Eltsov, A.I. Smolentsev, Y.V. Mironov, M.A. Shestopalov, J. Coord. Chem. 69 (2016) 841-850.

26. B.K. Roland, H.D. Selby, J.R. Cole, Z. Zheng, Dalton Trans. 0 (2003) 4307-4312

27. T. Yoshimura, K. Umakoshi, Y. Sasaki, S. Ishizaka, H.-B. Kim, N. Kitamura, Inorg. Chem. 39 (2000) 1765-1772.

28. A.A. Ivanov, D.I. Konovalov, T.N. Pozmogova, A.O. Solovieva, A.R. Melnikov, K.A. Brylev, N.V. Kuratieva, V.V. Yanshole, K. Kirakci, K. Lang, S.N. Cheltygmasheva, N. Kitamura, L.V. Shestopalova, Y.V. Mironov, M.A. Shestopalov, Inorg. Chem. Front. (2019) DOI: 10.1039/C8QI01216D.

29. Y. Molard, F. Dorson, K.A. Brylev, M.A. Shestopalov, Y. Le Gal, S. Cordier, Y.V. Mironov, N. Kitamura, C. Perrin, Chem. Eur. J. 16 (2010) 5613-5619.

30. B.K. Roland, W.H. Flora, M.D. Carducci, N.R. Armstrong, Z. Zheng, J. Clust. Sci. 14 (2003) 449-458.

31. Y.V. Mironov, K.A. Brylev, M.A. Shestopalov, S.S. Yarovoi, V.E. Fedorov, H. Spies, H.J. Pietzsch, H. Stephan, G. Geipel, G. Bernhard, W. Kraus, Inorg. Chim. Acta 359 (2006) 11291134.

32. M.A. Shestopalov, A.A. Ivanov, A.I. Smolentsev, Y.V. Mironov, J. Struct. Chem. 55 (2014) 139-141.

(C2019, Elsevier. This manuscript version is made available under the CC-BY-NC-ND 4.0 license http://creativecommons.org/licenses/by-nc-nd/4.0/ 
33. C.P. Chin, Y. Ren, J. Berry, S.A. Knott, C.C. McLauchlan, L.F. Szczepura, Dalton Trans. 47 (2018) 4653-4660

34. W.B. Wilson, K. Stark, D.B. Johnson, Y. Ren, H. Ishida, D.L. Cedeño, L.F. Szczepura, Eur. J. Inorg. Chem. (2014) 2254-2261.

35. B.K. Roland, C. Carter, Z. Zheng, J. Am. Chem. Soc. 124 (2002) 6234-6235.

36. H.D. Selby, P. Orto, M.D. Carducci, Z. Zheng, Inorg. Chem. 41 (2002) 6175-6177.

37. H.D. Selby, Z. Zheng, T.G. Gray, R.H. Holm, Inorg. Chim. Acta 312 (2001) 205-209.

38. L. Alvarado-Soto, R. Ramírez-Tagle, Materials 8 (2015) 3938-3944.

39. A.A. Ivanov, N.V. Kuratieva, M.A. Shestopalov, Y.V. Mironov, J. Struct. Chem. 58 (2017) 989-993.

40. A.A. Ivanov, M.A. Shestopalov, K.A. Brylev, V.K. Khlestkin, Y.V. Mironov, Polyhedron 81 (2014) 634-638.

41. Bruker, APEX2 (Version 1.08), SAINT (Version 07.03), SADABS (Version 02.11), SHELXTL (Version 06.12), Bruker AXS Inc., Madison, WI, USA (2004).

42. A. Savitzky, M.J.E. Golay, Anal. Chem. 36 (1964) 1627-1639.

43. M.A. Shestopalov, S. Cordier, O. Hernandez, Y. Molard, C. Perrin, A. Perrin, V.E. Fedorov, Y.V. Mironov, Inorg. Chem. 48 (2009) 1482-1489.

44. M.A. Shestopalov, Y.V. Mironov, K.A. Brylev, V.E. Fedorov, Russ. Chem. Bull. 57 (2008) 1644-1649.

45. A.Y. Ledneva, N.G. Naumov, A.V. Virovets, S. Cordier, Y. Molard, J. Struct. Chem. 53 (2012) 132-137.

46. N. Kitamura, Y. Kuwahara, Y. Ueda, Y. Ito, S. Ishizaka, Y. Sasaki, K. Tsuge, S. Akagi, Bull. Chem. Soc. Jpn. 90 (2017) 1164-1173.

(C2019, Elsevier. This manuscript version is made available under the CC-BY-NC-ND 4.0 license http://creativecommons.org/licenses/by-nc-nd/4.0/ 


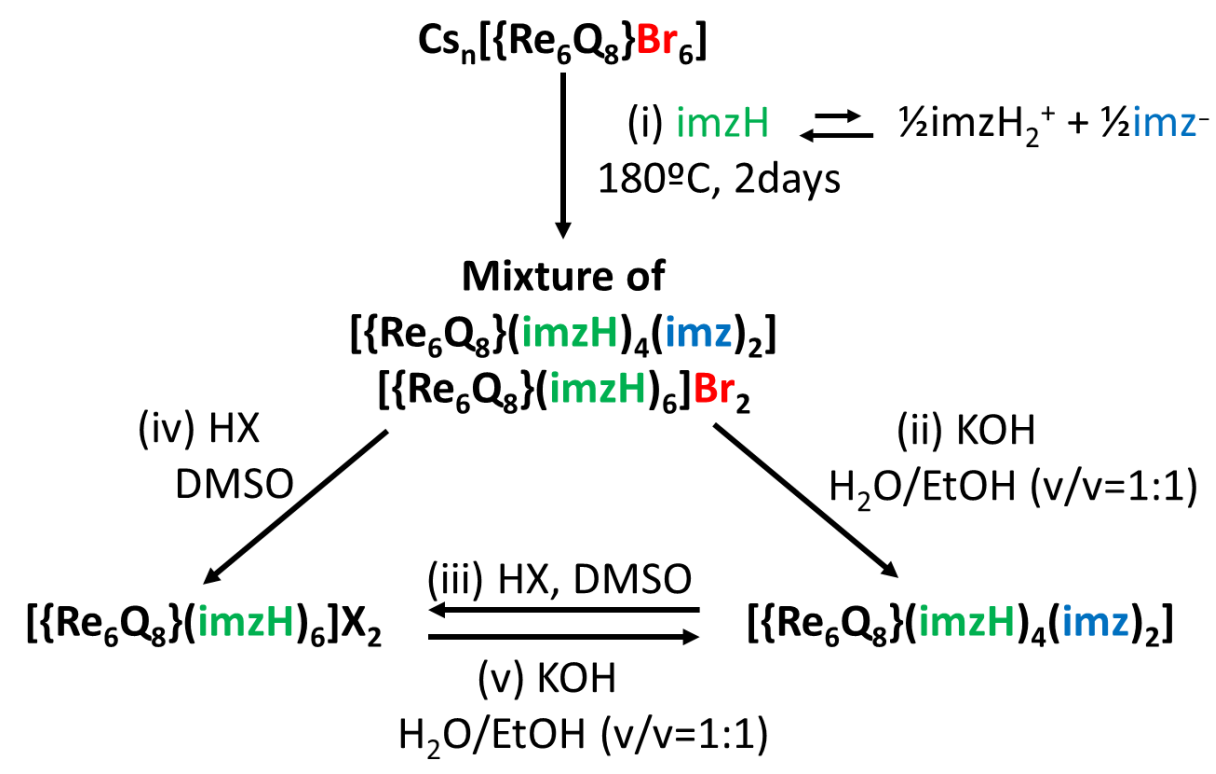

Scheme 1. Substances conversion scheme. 


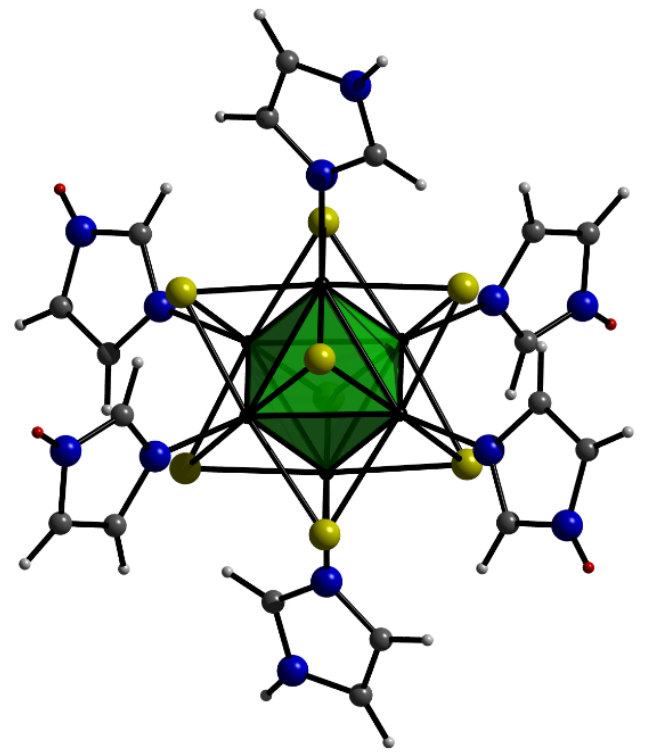

Figure 1. The structure of the $\left[\left\{\operatorname{Re}_{6} \mathrm{Q}_{8}\right\}(\mathrm{imzH})_{4}(\mathrm{imz})_{2}\right]$ in compound 1. Colour code: $\operatorname{Re}$ (black), $\mathrm{Q}$ (yellow), N (blue), C (charcoal), H (white), $\mathrm{H}$ with occupation $1 / 2$ (red), octahedron $\mathrm{Re}_{6}$ (green). 


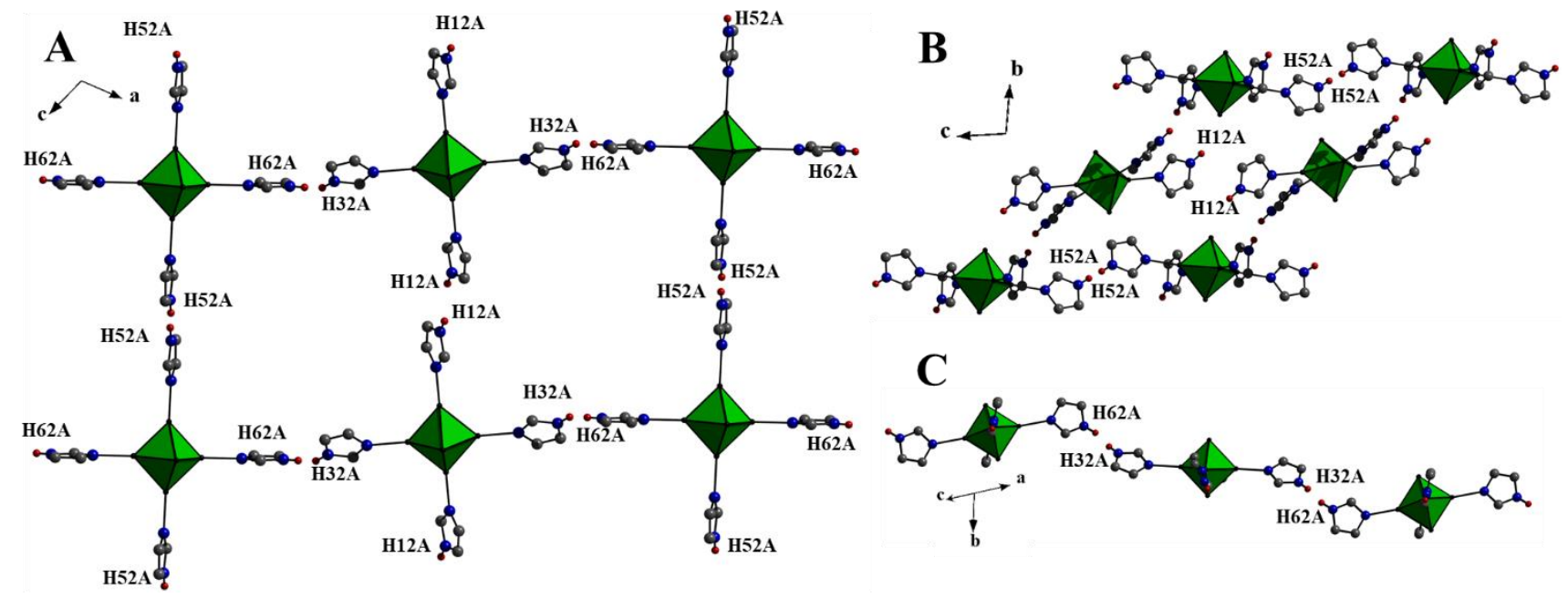

Figure 2. Packing in the crystal structure of 1. Colour code: Re (black), N (blue), C (charcoal), H with occupation $1 / 2$ (red), octahedron $\mathrm{Re}_{6}$ (green). Sulphur atoms, non-disordered hydrogen and ligands without disordered hydrogen are omitted for clarity. 

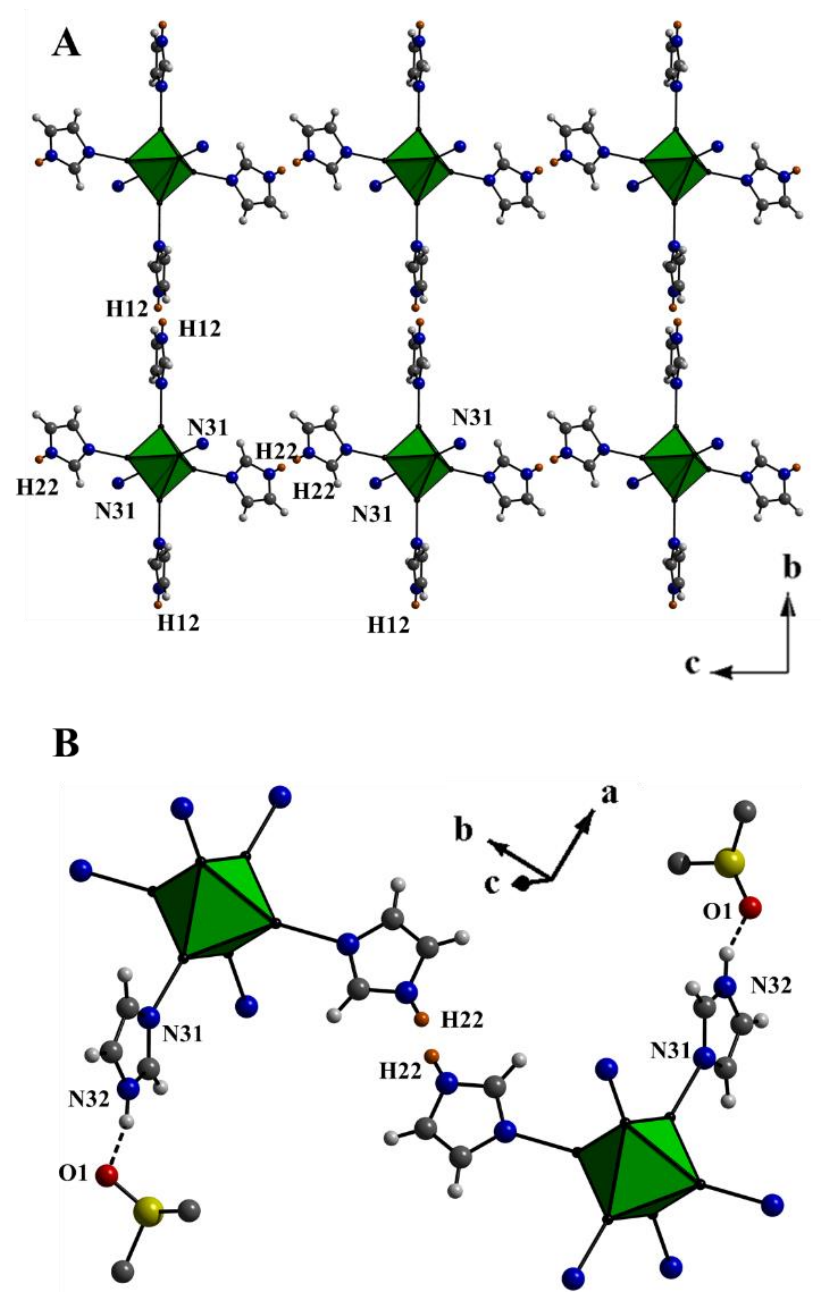

Figure 3. Packing (A) and hydrogen bonding (B) in the crystal structure of 1-2DMSO. Colour code: Re (black), N (blue), C (charcoal), H with occupation 1/2 (orange), O (red), S (yellow,) octahedron $\operatorname{Re}_{6}$ (green). Sulphur atoms in the cluster core and other ligands are omitted for clarity. 


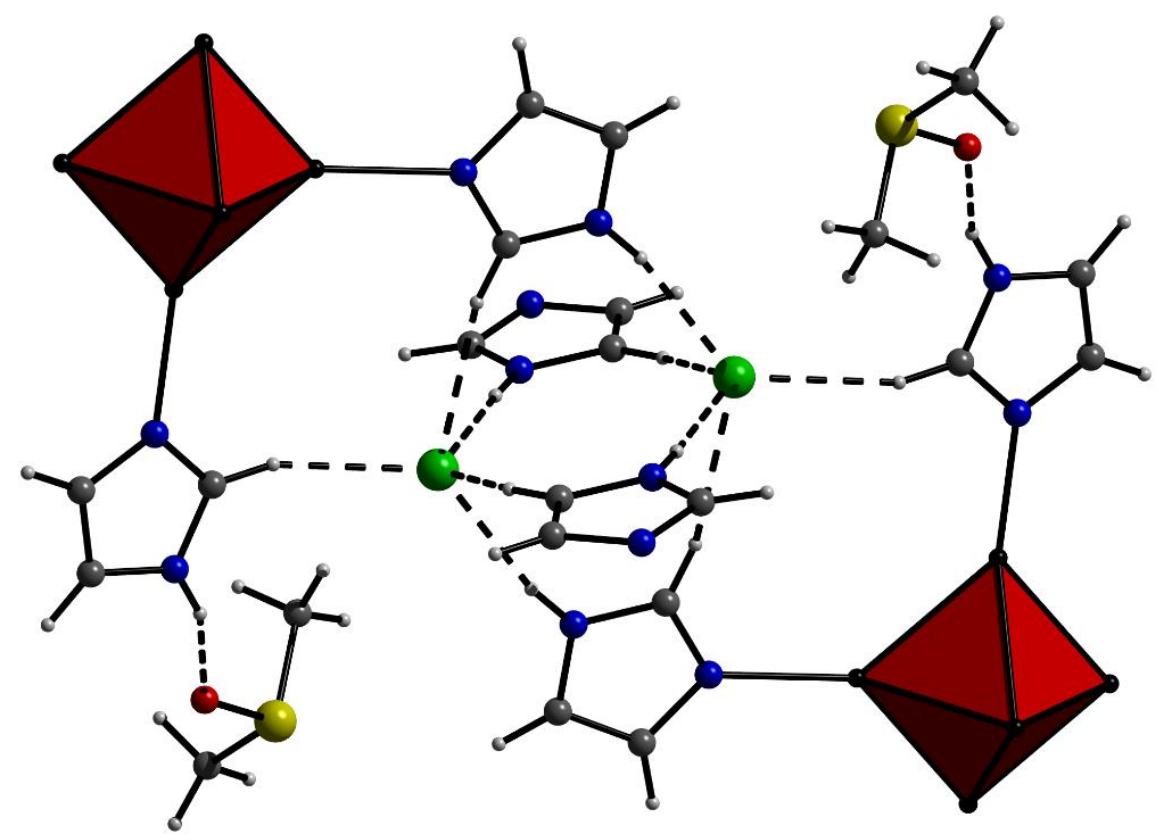

Figure 4. The system of hydrogen bonds in the crystal structure of $2 \cdot 2 \mathrm{HX} \cdot 4 \mathrm{DMSO}(\mathrm{X}=\mathrm{Cl}, \mathrm{Br})$. Colour code: Re (black), N (blue), C (charcoal), O (red), S (yellow), X (green), H (white), octahedron $\operatorname{Re}_{6}$ (red). 

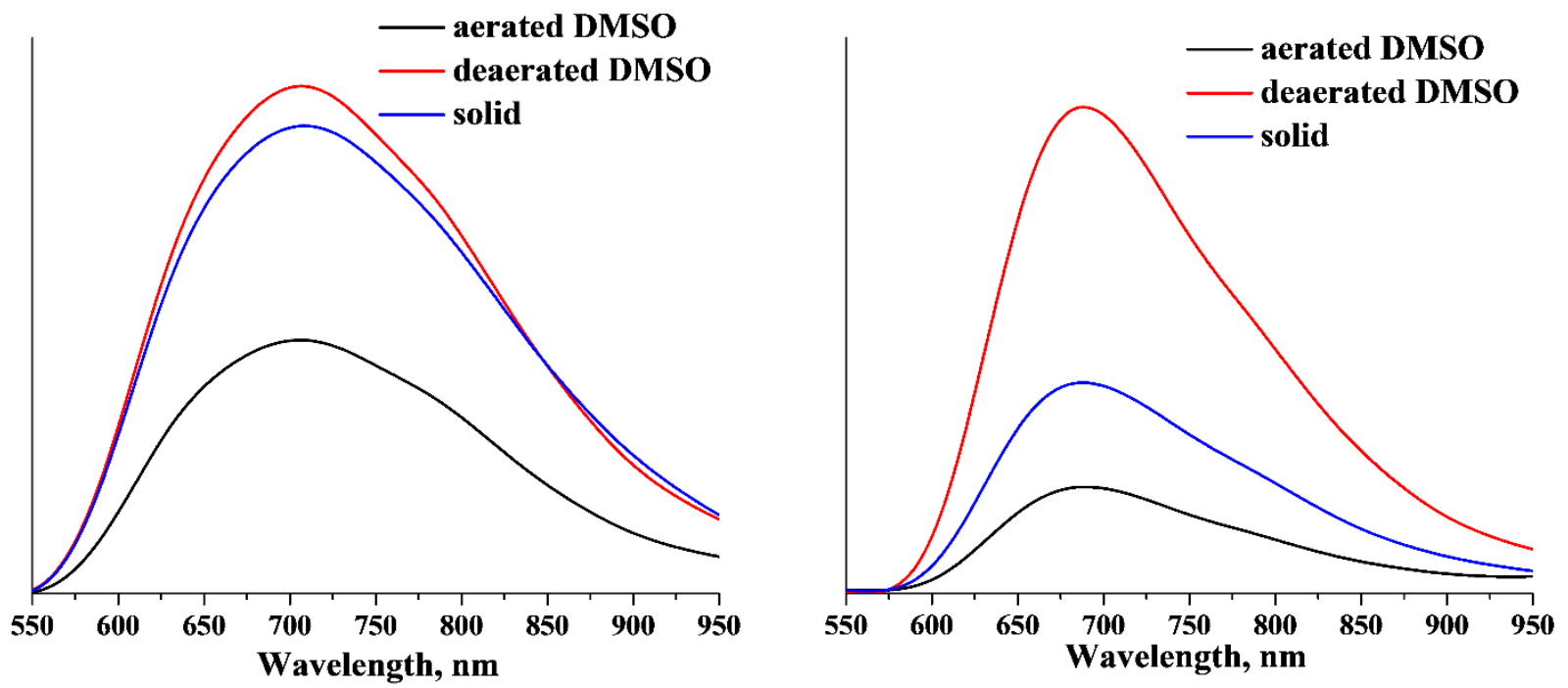

Figure 5. Smoothed emission spectra of $\mathbf{1}$ (left) and $\mathbf{2}$ (right) in the solid state and in aerated and deaerated DMSO solutions. 
Table 1. Crystallographic data, data collection and refinement parameters for 1, 1.2DMSO, 2.2HCl$\cdot 4 \mathrm{DMSO}$ and $\mathbf{2} \cdot 2 \mathrm{HBr} \cdot 4 \mathrm{DMSO}$.

\begin{tabular}{|c|c|c|c|c|}
\hline & 1 & 1.2DMSO & $\mathbf{2} \cdot 2 \mathrm{HCl} \cdot 4 \mathrm{DMSO}$ & $\mathbf{2} \cdot 2 \mathrm{HBr} \cdot 4 \mathrm{DMSO}$ \\
\hline $\begin{array}{l}\text { Empirical } \\
\text { formula }\end{array}$ & $\mathrm{C}_{18} \mathrm{H}_{22} \mathrm{~N}_{12} \operatorname{Re}_{6} \mathrm{~S}_{8}$ & $\mathrm{C}_{22} \mathrm{H}_{34} \mathrm{~N}_{12} \mathrm{O}_{2} \mathrm{Re}_{6} \mathrm{~S}_{10}$ & $\mathrm{C}_{26} \mathrm{H}_{48} \mathrm{Cl}_{2} \mathrm{~N}_{12} \mathrm{O}_{4} \mathrm{Re}_{6} \mathrm{~S}_{4} \mathrm{Se}_{8}$ & $\mathrm{C}_{26} \mathrm{H}_{48} \mathrm{Br}_{2} \mathrm{~N}_{12} \mathrm{O}_{4} \mathrm{Re}_{6} \mathrm{~S}_{4} \mathrm{Se}_{8}$ \\
\hline $\begin{array}{l}\text { Formula } \\
\text { weight }\end{array}$ & 1780.16 & 1936.41 & 2540.78 & 2629.70 \\
\hline $\begin{array}{l}\text { Temperature } \\
(\mathrm{K})\end{array}$ & $150(2)$ & $150(2)$ & $150(2)$ & $150(2)$ \\
\hline $\begin{array}{l}\text { Crystal size } \\
\left(\mathrm{mm}^{3}\right)\end{array}$ & $0.12 \times 0.12 \times 0.02$ & $0.25 \times 0.07 \times 0.05$ & $0.10 \times 0.06 \times 0.02$ & $0.44 \times 0.05 \times 0.05$ \\
\hline $\begin{array}{l}\text { Crystal } \\
\text { system }\end{array}$ & Triclinic & Monoclinic & Triclinic & Triclinic \\
\hline Space group & $P \overline{1}$ & $P 2{ }_{1} / \mathrm{c}$ & $P \overline{1}$ & $P \overline{1}$ \\
\hline$Z$ & 1 & 2 & 1 & 1 \\
\hline \multicolumn{5}{|l|}{$\begin{array}{l}\text { Unit cell } \\
\text { dimensions }\end{array}$} \\
\hline$a(\AA)$ & $10.9311(2)$ & $11.6291(6)$ & $11.1802(9)$ & $11.0938(5)$ \\
\hline$b(\AA)$ & $11.5522(3)$ & $14.2902(8)$ & $11.6187(10)$ & $11.6179(4)$ \\
\hline c $(\AA)$ & $14.0929(3)$ & $12.9396(7)$ & $12.1118(11)$ & $12.1781(5)$ \\
\hline$\alpha\left(^{(}\right)$ & $90.6850(10)$ & 90 & $62.030(3)$ & $63.671(1)$ \\
\hline$\beta\left(^{\circ}\right)$ & $109.1240(10)$ & 107.097(2) & $74.058(3)$ & $74.021(1)$ \\
\hline$\gamma\left({ }^{\circ}\right)$ & $109.0990(10)$ & 90 & $85.394(3)$ & $85.439(1)$ \\
\hline $\begin{array}{l}\text { Volume } \\
\left(\AA^{3}\right)\end{array}$ & $1574.64(6)$ & 2055.30(19) & $1333.9(2)$ & $1357.04(9)$ \\
\hline $\begin{array}{l}\mathrm{D}_{\text {calcd. }}\left(\mathrm{g} \cdot \mathrm{cm}^{-}\right. \\
3)\end{array}$ & 3.755 & 3.129 & 3.163 & 3.218 \\
\hline$\mu\left(\mathrm{mm}^{-1}\right)$ & 23.537 & 18.148 & 19.316 & 20.361 \\
\hline$\theta$ range $\left(^{\circ}\right)$ & $1.54-27.53$ & $2.18-27.55$ & $1.90-27.60$ & $1.91-27.61$ \\
\hline $\begin{array}{l}\text { Indices } \\
\text { ranges }\end{array}$ & $\begin{array}{l}-14 \leq h \leq 14 \\
-15 \leq k \leq 15 \\
-18 \leq l \leq 18\end{array}$ & $\begin{array}{l}-15 \leq h \leq 15 \\
-18 \leq k \leq 17 \\
-14 \leq l \leq 16\end{array}$ & $\begin{array}{l}-14 \leq h \leq 14 \\
-12 \leq k \leq 15 \\
-14 \leq l \leq 15\end{array}$ & $\begin{array}{l}-14 \leq h \leq 14 \\
-15 \leq k \leq 15 \\
-15 \leq l \leq 15\end{array}$ \\
\hline $\begin{array}{l}\text { Reflections } \\
\text { collected }\end{array}$ & 17439 & 17450 & 13051 & 14519 \\
\hline $\begin{array}{l}\text { Unique } \\
\text { reflections }\end{array}$ & $7242\left(R_{\mathrm{int}}=0.0275\right)$ & $4732\left(R_{\text {int }}=0.0357\right)$ & $6147\left(R_{\mathrm{int}}=0.0479\right)$ & $6274\left(R_{\mathrm{int}}=0.0266\right)$ \\
\hline $\begin{array}{l}\text { Observed } \\
\text { reflections }\end{array}$ & $6367[I>2 \sigma(I)]$ & $3819[I>2 \sigma(I)]$ & $3588[I>2 \sigma(I)]$ & $5004[I>2 \sigma(I)]$ \\
\hline $\begin{array}{l}\text { Parameters } \\
\text { refined }\end{array}$ & 397 & 252 & 284 & 284 \\
\hline$R\left[F^{2}>\right.$ & $R_{l}=0.0223$ & $R_{l}=0.0393$ & $R_{l}=0.0413$ & $R_{l}=0.0348$ \\
\hline $\left.2 \sigma\left(F^{2}\right)\right]$ & $w R_{2}=0.0481$ & $w R_{2}=0.1000$ & $w R_{2}=0.0787$ & $w R_{2}=0.0988$ \\
\hline $\begin{array}{l}R\left(F^{2}\right) \text { (all } \\
\text { data) }\end{array}$ & $\begin{array}{c}R_{1}=0.0285 \\
w R_{2}=0.0497\end{array}$ & $\begin{array}{c}R_{1}=0.0546 \\
w R_{2}=0.1056\end{array}$ & $\begin{array}{c}R_{1}=0.0929 \\
w R_{2}=0.0884\end{array}$ & $\begin{array}{c}R_{1}=0.0467 \\
w R_{2}=0.1042\end{array}$ \\
\hline $\begin{array}{l}\text { Goodness- } \\
\text { of-fit on } F^{2}\end{array}$ & 1.041 & 1.062 & 0.922 & 1.138 \\
\hline $\begin{array}{l}\Delta \rho_{\max }, \Delta \rho_{\min } \\
\left(\mathrm{e} \cdot \AA^{-3}\right)\end{array}$ & $2.398,-1.237$ & $3.879,-2.043$ & $2.356,-1.761$ & $2.717,-2.017$ \\
\hline
\end{tabular}

(C2019, Elsevier. This manuscript version is made available under the CC-BY-NC-ND 4.0 license http://creativecommons.org/licenses/by-nc-nd/4.0/ 
(C2019, Elsevier. This manuscript version is made available under the CC-BY-NC-ND 4.0 license http://creativecommons.org/licenses/by-nc-nd/4.0/ 
Table 2. Spectroscopic and photophysical parameters of cluster complexes $\mathbf{1}$ and $\mathbf{2}$.

\begin{tabular}{|c|c|c|c|c|c|c|c|}
\hline \multirow{3}{*}{ Compound } & & \multicolumn{4}{|c|}{ In DMSO solutions } & \multirow{2}{*}{\multicolumn{2}{|c|}{ In solid state }} \\
\hline & & Aerated & & Dea & ted & & \\
\hline & $\lambda_{e m} / \mathrm{nm}$ & $\tau_{e m} / \mu \mathrm{s}(\mathrm{A})$ & $\Phi_{e m}$ & $\tau_{e m} / \mu \mathrm{s}$ & $\Phi_{e m}$ & $\tau_{e m} / \mu \mathrm{s}(\mathrm{A})$ & $\Phi_{e m}$ \\
\hline 1 & 707 & 7.1 & 0.06 & 15.3 & 0.12 & $\begin{array}{l}\tau_{1}=0.2(0.74) \\
\tau_{2}=5.3(0.12) \\
\tau_{3}=8.8(0.14)\end{array}$ & 0.11 \\
\hline 2 & 688 & $\begin{array}{l}\tau_{1}=1.2(0.56) \\
\tau_{2}=3.6(0.44)\end{array}$ & 0.03 & 19.6 & 0.14 & $\begin{array}{c}\tau_{1}=1.2(0.49) \\
\tau_{2}=3.6(0.50) \\
\tau_{3}=11.4(0.01)\end{array}$ & 0.06 \\
\hline
\end{tabular}

